E D I T O R I A L

\title{
HISTÓRIA ORAL: DIMENSÕES PÚBLICAS NO TEMPO PRESENTE
}

Oral history: public dimensions in the present time

Historia oral: dimensiones públicas en la historia del tiempo presente

\author{
JUNIELE RABÊLO DE ALMEIDA ${ }^{\text {I* }}$ \\ VIVIAN LUIZ FONSECA ${ }^{\mathrm{II**}}$
}

https://doi.org/10.1590/S2178-149420210301

'Universidade Federal Fluminense - Niterói (RJ), Brasil.

*Doutora em História Social, Universidade de São Paulo (junielerabelo@gmail.com)

(D) https://orcid.org/0000-0001-9468-9192

"Fundação Getúlio Vargas, Universidade do Estado do Rio de Janeiro - Rio de Janeiro (RJ), Brasil.

**Doutora em História, Política e Bens Culturais, Fundação Getúlio Vargas (vivianluizfonseca@gmail.com)

(D) https://orcid.org/0000-0002-0943-9752 


\section{HISTÓRIA ORAL: DIMENSÕES PÚBLICAS NO TEMPO PRESENTE}

$\mathrm{E}$ ste dossiê contempla estudos sobre história oral com base em pesquisas que assumem os desafios colocados contemporaneamente a essa metodologia de pesquisa e produção de fontes. Metodologia desenvolvida desde fins dos anos 1950 e amplamente utilizada e consolidada ao redor do mundo, a história oral chega ao século XXI catalisada pelas discussões da história pública, assim como pelas novas tecnologias, que colocam em questão novas formas de gravação, interação, preservação e difusão das narrativas orais e audiovisuais. Nesse sentido, este dossiê traz, particularmente, artigos que tencionam essas dimensões, com reflexões sobre suas interações e respostas da história oral às questões do tempo presente: por estudos temáticos, trajetórias de vida ou tradição oral.

Os textos afirmam o dinâmico movimento da história oral e os seus entrecruzamentos com a historiografia. Pela oralidade, é possível observar o trabalho de memória - escoIhas narrativas referentes às formas como os sujeitos históricos significam as dimensões do público no tempo presente. Na história oral, dissensos e consensos, presentes nas memórias coletivas, catalisam práticas sociais. Lembranças, silêncios e esquecimentos expressam questões socialmente vivas em estudos que mobilizam múltiplos itinerários dos usos do passado. Ao evidenciarem as narrativas dos sujeitos históricos, os autores desenvolveram análises pela constituição de fontes que desempenham papel fundamental nas reflexões sobre "comunidades de sentido" e suas conexões temporais entre passado, presente e expectativas futuras.

Ante os debates públicos contemporâneos, este dossiê é organizado de modo que contemple artigos que contribuam para avançar na discussão teórico-conceitual e prática do movimento da história oral, pelo ponto de vista da investigação científica interdisciplinar. Os autores são pesquisadores reconhecidos por seus trabalhos na interface memória e oralidade - vinculados a diversas instituições acadêmicas brasileiras, situadas nas regiões Nordeste, Centro-Oeste e Sudeste. 0 presente número conta também com uma autora e uma entrevistada americanas e três entrevistados franceses, propiciando discussões transnacionais. Os textos são fruto de pesquisas ligadas a diferentes núcleos, laboratórios e grupos de história oral — já consolidados nacional e internacionalmente - muitas vezes relacionados com ações extensionistas e práticas educativas. 0 dossiê é composto de sete artigos, duas entrevistas e uma contribuição especial.

0 texto de abertura, "Uma história oral em três tempos: relações, construções narrativas, usos práticos da memória", de Ricardo Santhiago e Daphne Patai, discute a interface história oral e pesquisa participativa. Trata-se de um projeto que coletou entrevistas de história oral, nos anos 2010, com mulheres que já haviam se narrado três décadas antes, em outro 
contexto de pesquisa (entrevistas realizadas pela professora Daphne Patai - University of Massachusetts - no Brasil dos anos 1980). Os depoimentos foram discutidos com base em questões metodológicas, problematizando as relações intersubjetivas estabelecidas em uma pesquisa projetada no tempo, e interpretativas, avaliando a construção sintagmática da narrativa da entrevistada Marialice: os padrões narrativos e os usos práticos de sua própria história.

Em seguida, o artigo "Pode a história oral ajudar a adiar o fim do mundo? COVID-19: tempo, testemunho e história", de Rodrigo de Azevedo Weimer e Carla Simone Rodeghero, analisa experiências da pandemia com foco na dimensão do testemunho e da temporalidade, pela realização de entrevistas possibilitadas por ferramentas de videoconferência em um contexto de isolamento social. Por meio desse entrecruzamento, traz instigantes questões acerca do ato de "testemunhar o testemunho" e seus significados no tempo presente. Os autores discutiram 18 depoimentos, realizados entre 2020 e 2021, em um projeto de história oral sobre o cotidiano da COVID-19, possibilitando reflexões sobre a história como vivência e como processo de construção do conhecimento.

0 terceiro artigo, "Um Comblin: historiografia, história oral e memória", de Antônio Montenegro, expõe o resultado da pesquisa sobre a trajetória e as perseguições perpetradas pela ditadura civil-militar contra o padre Comblin — figura-chave da Teologia da Libertação no Brasil. 0 texto apresenta reflexões teórico-metodológicas em torno do uso de entrevistas na historiografia. A pesquisa traz instigantes abordagens para a relação Igreja e ditadura ao confrontar relatos de história oral, historiografia e memória.

Já o texto "Contam que houve uma porção de enforcados. E as caveiras espetadas nos postes", de Marcos Andrade Ferreira, discute a relação entre história, literatura e memória, procurando demonstrar a importância das duas fontes para construir a representação historiográfica em relação à Revolta de Carrancas, ocorrida em 1833 (sul de Minas Gerais). Os resultados da pesquisa de campo na região, sobre a memória oral dessa insurreição, foram observados com base na análise do poema "Levante", de Oswald de Andrade. Tal poema é associado à memória senhorial e coletiva da Revolta de Carrancas - memória que atravessou os séculos, chegando aos dias atuais. A referida memória senhorial confunde-se muitas vezes com a própria memória histórica, questão central nos debates sobre história pública — posições em jogo nas disputas sobre os usos do passado.

0 artigo seguinte, "As vozes da memória empresarial: a experiência do Grupo Globo", escrito por Silvia Fiuza e Ana Paula Goulart Ribeiro, aborda a experiência de história oral realizada no âmbito das áreas de memória das empresas brasileiras, especialmente no Grupo Globo. As autoras problematizam a seletividade e o enquadramento da memória, a existência de unidades narrativas que sintetizam experiências e ajudam a compreender os acontecimentos 
e a sinergia entre produções audiovisuais e narrativas de história oral. 0 texto traz reflexões sobre os usos do passado em nossos dias e os lugares produtores de suas narrativas.

No penúltimo artigo, intitulado "Relações de gênero na guerrilha: a configuração dos espaços de luta", Eloisa Barroso aborda o papel das mulheres não apenas na guerrilha, mas na história brasileira. 0 texto apresenta as narrativas e as relaciona com as questões teóricas e com a historiografia. A análise dos dados colhidos perpassou por categorias de análise tais como identidade, representações, experiência e gênero na construção da trajetória de militância dessas mulheres no período. Por meio das experiências das mulheres guerrilheiras, 0 texto percorreu a diversidade de espaços e tempos nos campos tanto do gênero como da luta política por meio da história oral.

0 artigo "História oral e patrimônio cultural" — redigido por Flávia Klausing Gervásio, Hilario Figueiredo Pereira Filho e Joseane Paiva Macedo - encerra a seção de artigos do dossiê. Apresenta reflexões instigantes sobre a trajetória do Projeto Memória Oral do Instituto do Patrimônio Histórico e Artístico Nacional (IPHAN). Três fases são discutidas: a primeira trata das entrevistas realizadas na década de 1980; a segunda, entre 2007 e 2020, discute a incorporação da metodologia de história oral no âmbito de um projeto de pesquisa formalmente estruturado; e a terceira observa o atual contexto, marcado pela pandemia da COVID-19, fomentando questões teórico-metodológicas para desenvolver o projeto ante os desafios do tempo presente.

Na seção "Contribuição especial" do dossiê, temos a edição de conversas com a historiadora Ismênia de Lima Martins, professora emérita da Universidade Federal Fluminense (UFF), sobre "Trajetória acadêmica, tempo presente e história oral" - conversas mediadas pelas professoras Ana Maria Mauad, Hebe Mattos e Juniele Rabêlo de Almeida. 0 diálogo foi iniciado em agosto de 2012 e retomado, de maneira remota dado o cenário pandêmico, em junho de 2021. Os primeiros diálogos marcaram-se pelas reflexões autobiográficas referentes à consolidação das pesquisas que entrecruzam história oral, uso de fotografias na pesquisa história, estudos regionais e tempo presente no Brasil. Em meio às adversidades da COVID-19 e aos problemas de saúde enfrentados pela professora Ismênia, as últimas conversas, ocorridas a distância, trouxeram o desejo de envolver a sua experiência no processo de criação, em 1982, do Laboratório de História Oral e Imagem (LABHOI/UFF) e a sua atuação no Programa de Pós-graduação em História (PPGH/UFF), fundado em 1971, perpassando as memórias sensiveis da sua formação e os processos de transformação da pesquisa e do ensino de história no Brasil.

0 dossiê conta ainda com duas entrevistas. A primeira, "Entrevista com Julie I. May", foi realizada por Valéria Barbosa de Magalhães em 2019. A narrativa aborda a constituição do acervo de história oral do Brooklyn Historical Society, atual Center for Brooklyn History. 
Na primeira parte, o texto apresenta a entrevistada e o acervo e, na segunda, o relato de Julie. 0 projeto de história oral do Center for Brooklyn History conta com uma coleção sobre a história do Brooklyn que ultrapassa 1.200 entrevistas, constituindo um dos principais acervos de memória do mundo.

Por fim, "Escrita do historiador: entrevista com C. Delacroix, F. Dosse e P. Garcia" foi realizada por Daiane Machado e Raphael Guilherme de Carvalho, em Paris, em novembro de 2019. Os entrevistadores fizeram, entre 2019 e 2020, estágios de pós-doutorado no Institut d'Histoire du Temps Présent (IHTP), na Unidade de Pesquisa Mista (ligada ao Centre National de la Recherche Scientifique - Universidade de Paris 8). A entrevista discute os mémoires de synthèse des activités scientifiques (resumos de atividades científicas) produzidos nos concursos para habilitations à diriger des recherches (autorizações ou acreditações para supervisionar pesquisas), na disciplina de história, que funciona desde o fim da década de 1980, para estudar a comunidade de historiadores contemporâneos na França. Delacroix, Dosse e Garcia, que constituem o núcleo do IHTP do programa, animam essas reflexões há mais de duas décadas.

Cada texto traz práticas e análises plurais — e, fundamentalmente, construções dialógicas da memória social que foram produzidas e difundidas no encontro dos diversos saberes (acadêmicos e não acadêmicos) expressos nas dimensões públicas do compartilhamento das experiências. Para além da divulgação de um conhecimento organizado e sistematizado pela ciência, a história oral encontra o seu lócus "público" na organização e mediação das memórias sociais.

Agradecemos imensamente aos autores que colaboraram com o dossiê: pesquisadoras e pesquisadores que trouxeram contribuições para os debates que entrecruzam história oral e história pública. A todos, desejamos uma boa leitura!

\section{REFERÊNCIAS BIBLIOGRÁFICAS}

ALMEIDA, J. R. Práticas de história pública: o movimento social e o trabalho de história oral. In: ALMEIDA, J. R.; MAUAD, A.; SANTHIAGO, R. (orgs.). História pública no Brasil: sentidos e itinerários. São Paulo: Letra e Voz, 2016. p. 47-56.

ALMEIDA, J. R. 0 que a história oral ensina à história pública. In: MAUAD, A.; SANTHIAGO, R.; BORGES, V. (orgs.). Que história pública queremos? São Paulo: Letra e Voz, 2018. p. 101-120. 